http://ejournal.upi.edu/index.php/jaz - e-mail: jurnal.zonasi@gmail.com dan jurnal zonasi@upi.edu doi.org/10.17509/jaz.v2i3.17877

\title{
PENERAPAN KONSEP HEALING ARCHITECTURE PADA RUMAH SAKIT TIPE D DI KABUPATEN KENDAL
}

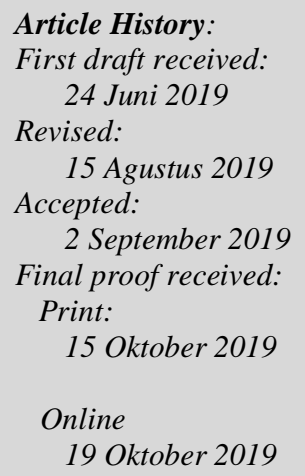

\author{
Shafira Azza ${ }^{1}$; Dita Ayu Rani Natalia ${ }^{2}$ \\ 1,2 Universitas Teknologi Yogyakarta, Yogyakarta, Indonesia \\ Jalan Glagahsari No. 63, D.I. Yogyakarta 55164 \\ Email: shafira02azza@gmail.com ; ditayurani@gmail.com
}

\begin{abstract}
Kendal Regency is a region in Central Java Province that has a large area with increasing number of resident. Increasing number of residents set off increasing number of disease but health facility in Kendal Regency is not available yet. Thus, health facility or hospital is needed in order to help healing process for the residents. Type D hospital is designed using the application of healing architecture concept because this concept will be really helpful for the patients in their healing process. Healing Architecture is implemented in the building of Type D Hospital with outdoor and indoor design thus creating an atmosphere that can influence the psychology and physic of the patients in healing process. The data was obtained through primary and secondary data collection. The primary data was done through interview, observation, location mapping, and documentation. Secondary data was collected from related agencies and literature study from journal or related paper. The result from the application of healing architecture concept on Type D Aisyiyah Hospital in Kendal Regency was showed off on the building façade, outdoor room, and indoor room of the hospital which is helpful in healing process by considering structure of building and utility for hospital needs.
\end{abstract}

Keywords: Healing Architecture, Hospital, Kendal Regency

\begin{abstract}
Abstrak: Kabupaten Kendal adalah salah satu kabupaten yang berada di Jawa Tengah yang memiliki wilayah yang cukup luas dengan perkembangan penduduk yang kian meningkat. Bertambahnya pertumbuhan penduduk menyebabkan semakin banyak pula penyakit yang berkembang tiap tahunnya, namun fasilitas kesehatan di Kabupaten Kendal masih kurang ketersediaannya sehingga diperlukan fasilitas kesehatan berupa rumah sakit untuk membantu penyembuhan masyarakat. Rumah sakit dengan tipe D dirancang menggunakan penerapan konsep healing architecture karena konsep ini sangat membantu pengguna terutama pasien dalam proses penyembuhan. Healing Architecture merupakan konsep penyembuhan yang dilakukan demi menciptakan bentuk dan lingkungan arsitektur yang memiliki aspek people, process and place. Healing Architecture diimplementasikan dalam bangunan Rumah Sakit tipe D di Kabupaten Kendal dengan desain ruang luar dan dalam sehingga menciptakan suasana yang dapat berpengaruh terhadap psikologi dan fisik terapi pasien dalam proses penyembuhan. Metode pengumpulan data menggunakan metode pengumpulan data primer yaitu berupa wawancara, pengamatan, pemetaan lokasi serta dokumentasi, dan metode pengumpulan data sekunder yaitu berupa data dari instansi yang terkait serta studi literatur terhadap jurnal atau karya ilmiah yang berkaitan. Hasil penerapan konsep healing architecture pada rumah sakit tipe D di Kabupaten Kendal diterapkan pada fasad bangunan, ruang luar dan ruang dalam pada rumah sakit yang dapat membantu proses penyembuhan pasien dengan mempertimbangkan struktur pada bangunan dan utilitas untuk kebutuhan rumah sakit.
\end{abstract}

Kata Kunci: Healing Architecture, Rumah Sakit Tipe D, Kabupaten Kendal

\section{Pendahuluan}

Kendal merupakan suatu kabupaten di Jawa Tengah yang memiliki lahan seluas $1.001,73 \mathrm{~km}^{2}$ serta memiliki jumlah penduduk yang cukup banyak. Seiring pergantian tahun, pertumbuhan penduduk kian naik 
namun tingkat kesehatan semakin menurun dikarenakan kurangnya fasilitas kesehatan yang disediakan untuk masyarakat.

Berdasarkan data Profil Kesehatan Kabupaten Kendal Tahun 2016, terdapat 10 macam penyakit yang mendominasi dan beberapa penyakit lainnya menyebar di wilayah Kabupaten Kendal. Pada kasus CNR tb, angka kesembuhan di tahun 2016 sebesar 76,80\% dengan penurunan dari tahun 2015 sebesar 78,45\%. Pada kasus kematian oleh HIV/AIDS meningkat pada tahun 2016 menjadi 31 kasus. Penemuan pneumonia balita terus mengalami peningkatan yaitu $1134,39 \%$ pada tahun 2016 dan 49,21 pada tahun 2015. Pada kasus kusta mengalami peningkatan dari tahun 2015 ke tahun 2016 sebesar 39,89\%. Penanganan diare sebesar 107,3\% yaitu sebanyak 22.092 kasus. Penanganan kasus DBD untuk tahun 2016 meningkat sebesar 1,9\%.

Pemerintah daerah memiliki misi untuk meningkatkan fasilitas kesehatan karena adanya permasalahan kesehatan yang sedang terjadi di Kabupaten Kendal. Dengan demikian, sangat diperlukan fasilitas kesehatan yakni berupa Rumah Sakit di Kabupaten Kendal.

Berdasarkan Undang-undang No. 44 Tahun 2009 tentang Rumah Sakit, rumah sakit adalah intuisi pelayanan kesehatan yang diselenggarakan perorangan secara paripurna dengan penyediaan pelayanan rawat inap, rawat jalan dan gawat darurat. Pengaturan diselenggaraakannya rumah sakit bertujuan untuk memudahkan akses masyarakat mendapatkan pelayanan kesehatan, perlindungan diberikan terhadap pasien, masyarakat, lingkungan rumah sakit dan sumber daya manusia di rumah sakit serta mutu dan mempertahankan standar pelayanan rumah sakit ditingkatkan.

Berdasarkan jumlah penduduk dan penyakit yang berkembang di Kabupaten Kendal dibutuhkan rumah sakit dengan tipe D. Rumah sakit dibedakan menjadi empat kategori berdasarkan kelasnya. Menurut Menteri Kesehatan Republik Indonesia dalam Surat Keputusan Nomor 134/MenKes/SK IV/1978 pasal 4 tentang Rumah Sakit Umum diklasifikasikan menjadi empat kelas menurut beban kerja dan fungsi Rumah Sakit, yaitu kelas A, kelas B, kelas C dan kelas D. Rumah sakit dengan tipe kelas D merupakan rumah sakit dengan fasilitas yang dimiliki dan pelayanan kesehatan yang diberikan yaitu tingkat pertama. Rumah sakit tipe D bersifat transisi karena dapat ditingkatkan menjadi rumah sakit dengan tipe C. Rumah sakit ini juga menerima tampungan pelayanan dari puskesmas. Jumlah kapasitas tempat tidur yang harus tersedia minimal 25 tempat tidur. Pelayanan yang diberikan pun tidak terlalu kompleks. Berdasarkan Peraturan Menteri Kesehatan Republik Indonesia Nomor 56 paragraf 4 tentang Klasifikasi Rumah Sakit Umum Kelas D, pelayanan yang ada di Rumah Sakit Kelas D meliputi pelayanan medik, pelayanan kefarmasian, pelayanan keperawatan dan kebidanan, pelayanan penunjang klinik, pelayanan penunjang nonklinik, pelayanan rawat inap.

Rumah sakit tipe D di Kabupaten Kendal membutuhkan rancangan dengan penerapan konsep bangunan yang mampu membantu memulihkan dan menyembuhkan penyakit baik secara mental maupun fisik. Dengan demikian, penerapan konsep healing architecture sangat mampu memenuhi kebutuhan perancangan rumah sakit karena adanya keterkaitan antara desain arsitektur dengan penyembuhan secara menyeluruh kedalam bangunan. Menurut Anand (2013) konsep healing architerture adalah gabungan dari hermitage dan modern hospital sehingga dapat tercipta rumah sakit yang maju di masa depan. Healing architecture memiliki tiga aspek yaitu people, process and place. Pencapaian konsep yakni dengan memberikan suasana yang membuat pengguna melupakan rasa sakit yaitu dengan memasukan suasana dengan tingkat aktivitas dan keramahan dalam bangunan rumah sakit. Perlunya penerapan healing architecture dikarenakan rumah sakit merupakan wadah masyarakat yang kurang sehat untuk menyelaraskan kondisi fisik dengan hati dan pikiran kedalam proses penyembuhan, serta tempat yang memungkinkan pasien dapat pulih cepat tanpa terbebani dalam lingkup. Sedangkan menurut Asma dan Sudarma (2017) healing architecture itu sendiri mengartikan sebagai proses yang membantu dalam penyembuhan pasien melalui elemen arsitektur yang berkaitan dengan aspek bentuk, warna dan alam ke bangunan sehingga kesembuhan pasien dapat tercipta.

Menurut Lou (2017) pada konsep healing architerture, fasilitas layanan kesehatan dirancang untuk meningkatkan kemampuan staf rumah sakit untuk memberikan perawatan dan efisiensi yang berkualitas tinggi yang berdampak pada pemulihan pasien dan efektivitas keseluruhan. Healing Architecture menunjukan bahwa lingkungan binaan memiliki kemampuan untuk memperngaruhi kesehatan dan kesejahteraan psikologis pasien. Fitur seperti kamar yang terang, akses pencahayaan alami, jendela besar, kehidupan tanaman lokal dan pemandangan luar ruangan dapat meningkatkan proses penyembuhan dan memberikan meningkatan psikologis dan fisik.

Menurut Mazaya dan Setyawan (2016) konsep eksterior yang membantu pasien dala penyembuhan dari segi desain bangunan memiliki efek untuk fisik dan psikologi yang meliputi pewarnaan, unsur alam, roofgarden, signage, dan clear visual. Sedangkan pada bagian interior bangunan, menurut Mulyati (2009) aplikasi warna pada desain interior mengambil warna dengan konsep tenang, sedangkan konsep segar diterapkan oleh warna muda dengan mengambil inspirasi alam. Pengaruh alam itu sendiri sangat baik yakni 
menurut Mustika dan Muffida (2017) unsur alam sangat penting untuk rumah sakit karena alam mempengaruhi psikologi pasien dalam proses penyembuhan.

\section{Metode Penelitian}

Metode penelitian yang digunakan dengan cara mengumpulkan data, analisis data, mengintrepersikan data dan pada bagian akhir dengan desain perancangan yang mengacu pada hasil analisis data. Ide atau gagasan mengenai penerapan konsep healing architecture pada rumah sakit tipe D di Kabupaten Kendal dilakukan dengan cara mengambil informasi umum yang kemudian diklasifikasikan menjadi khusus. Maka data yang dihasilkan menentukan ide yang dirancang dengan tema Penerapan Konsep Healing Architecture Pada Rumah Sakit Tipe D di Kabupaten Kendal.

Metode pengumpulan data menggunakan data primer dan sekunder. Pengumpulan data primer didapat secara langsung dari hasil pengamatan di lokasi site di daerah Kabupaten Kendal. Teknik yang dilakukan yaitu melakukan wawancara dengan pegawai Dinas Kesehatan Kabupaten Kendal yang menangani perencanaan Rumah Sakit, mengamati lokasi yang akan dibangun, memetakan titik lokasi site, dan mendokumentasikan kondisi site dengan lingkungan sekitar.

Pada pengumpulan data sekunder dilakukan dengan kerjasama terhadap instansi-instansi terkait. Data sekunder yang diperlukan yaitu data yang diperoleh dari Dinas Kesehatan Kabupaten Kendal berupa data lokasi site dan studi kelayakan pembangunan rumah sakit, serta studi literatur berupa pengumpulan data berdasarkan sumber yang ada yakni berupa buku, artikel, tugas akhir, hands out dan karya ilmiah lainnya.

\section{Hasil dan Pembahasan}

\subsection{Analisis}

Analisis sangat diperlukan untuk merancang suatu bangunan agar dapat tercipta sesuai kebutuhan pengguna.

1. Analisa dan respon matahari berpengaruh terhadap pencahayaan pada ruang dalam dan luar bangunan sesuai dengan kebutuhannya yang dapat dilihat pada gambar 1 .

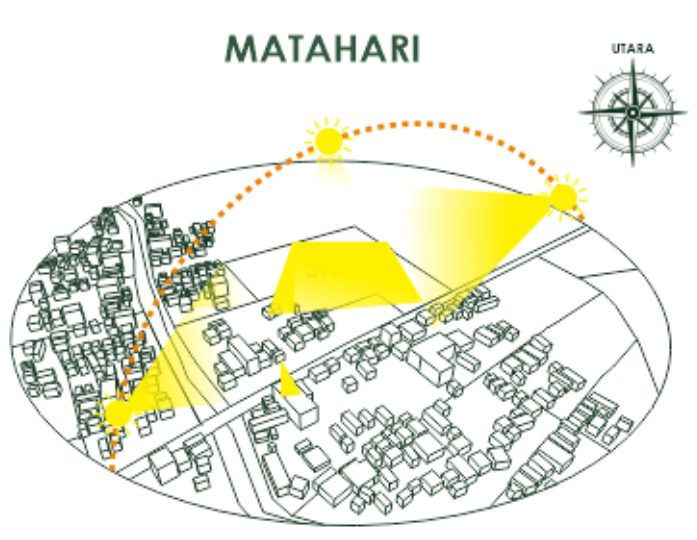

Site mendapatkan sinar matahari penuh tanpa ada halangan dikarenakan lingkungan sekitar site masih asri dan fidak terdapat bangunan tinggi
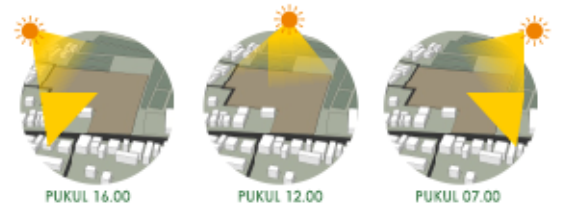

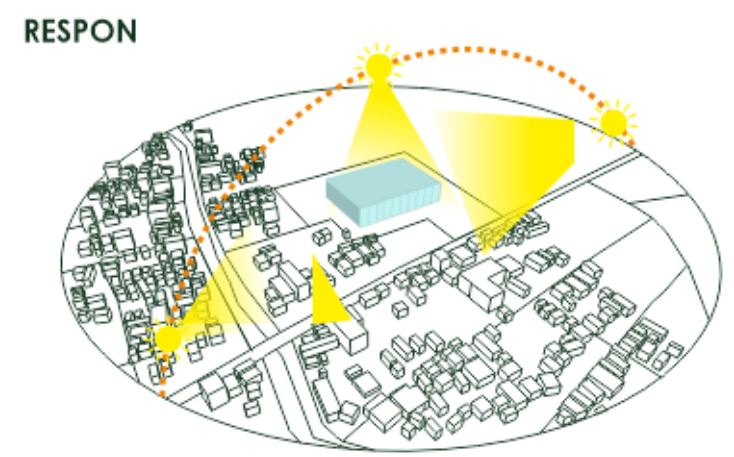

Bangunan pada site nantinya menghadap ke selatan untuk mengurangi intensitas cahaya secara langsung. Pemberian shading pada jendela pada bagian timur dan barat, sehingga matahari tidak langsung masuk ke dalam ruangan. Penggunaan secondary skin pada bangunan dan pemberian jendela dengan penutup zigzag dengan maksud memasukan cahaya secara tidak langsung, serta penambahan tanaman pada bagian barat dan timur unfuk menyaring sinar matahari secara langsung

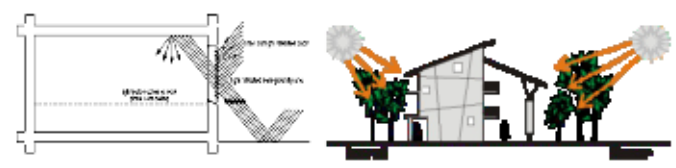

Gambar 1. Analisa dan Respon Matahari

Sumber: analisis, 2019

2. Analisa dan respon angin yang dimana sangat diperlukan sirkulasi angin sehingga udara pada dalam dan luar ruangan dapat terganti setiap waktu yang dapat dilihat pada gambar 2 . 


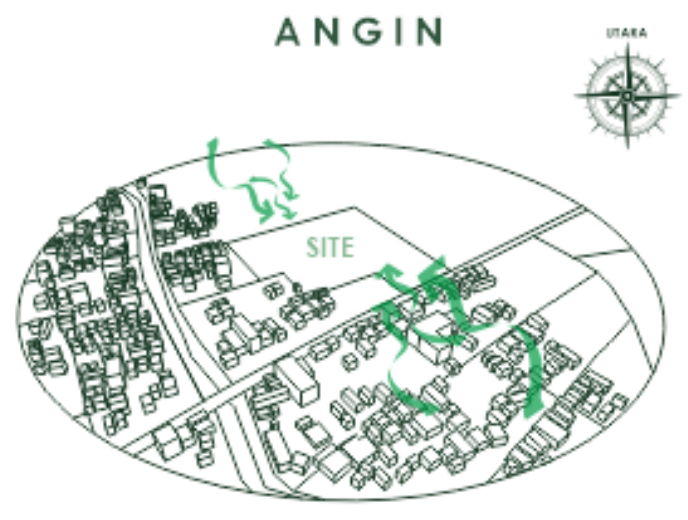

Angin berasal dari utara dan selatan site yang mampu memasuki site dengan leluasa sehingga site mendapatkan angin secara maksimal

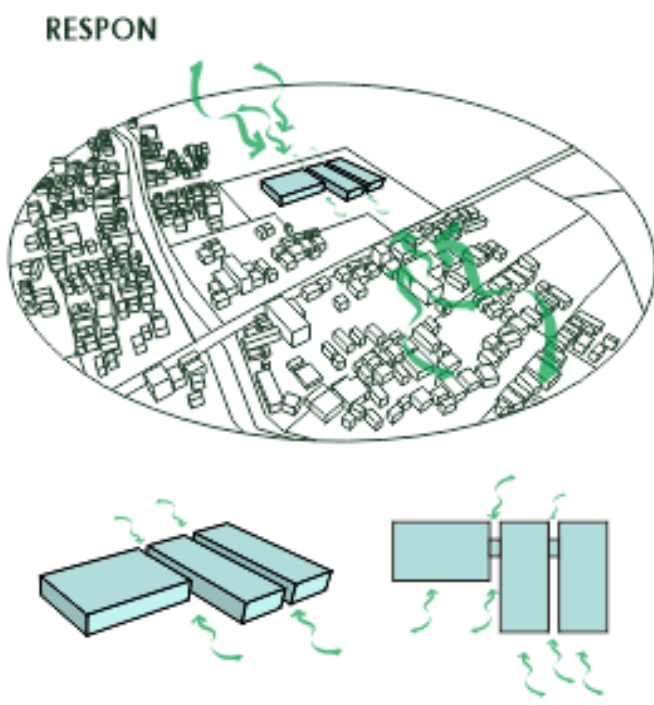

Bangunan pada site nantinya diberi void pada area selatan dan utara, sehingga angin dari arah tersebut ke dalam bangunan. Pada bagian fimur dan barat bangunan juga diberi void untuk meneruskan sirkulasi angin agar dapat merata ke seluruh bangunan.

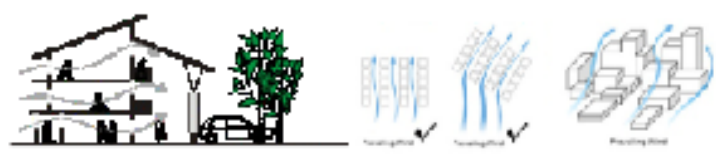

Gambar 2. Analisa dan Respon Angin

Sumber: analisis, 2019

3. Analisa dan respon aksesibilitas sangat dibutuhkan untuk memudahkan sirkulasi dan pencapaian ke bangunan yang dapat dlihat pada gambar 3 .

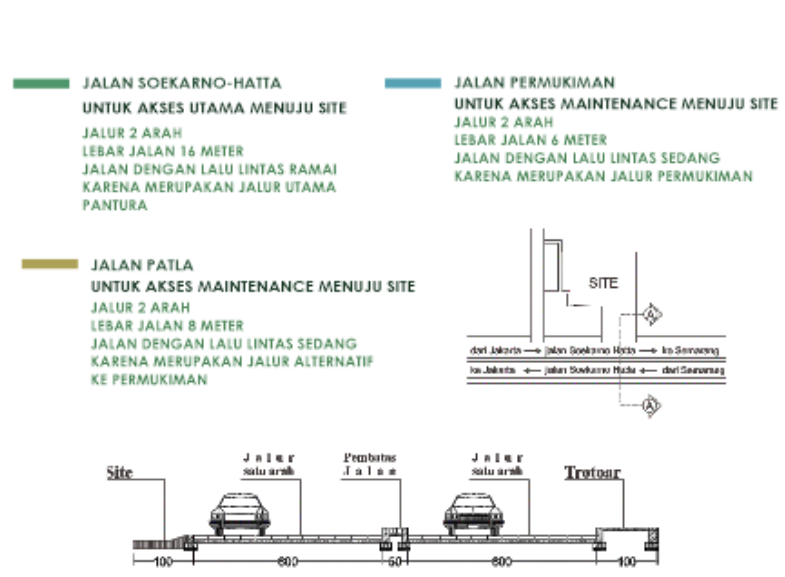

\section{RESPON}

Pemisahan akses masuk utama dan servis berguna untuk kemudahan dan kebebasan jalur yang nantinya akan dipakai oleh pengguna. Pada akses utama terdapat pada bagian depan site dari Jalan Soekarno Hatta menuju site yang merupakan jalan raya / jalan utama (jalur Pantura), sedangkan untuk akses servis berada pada bagian samping site yaitu dari jalan permukiman.

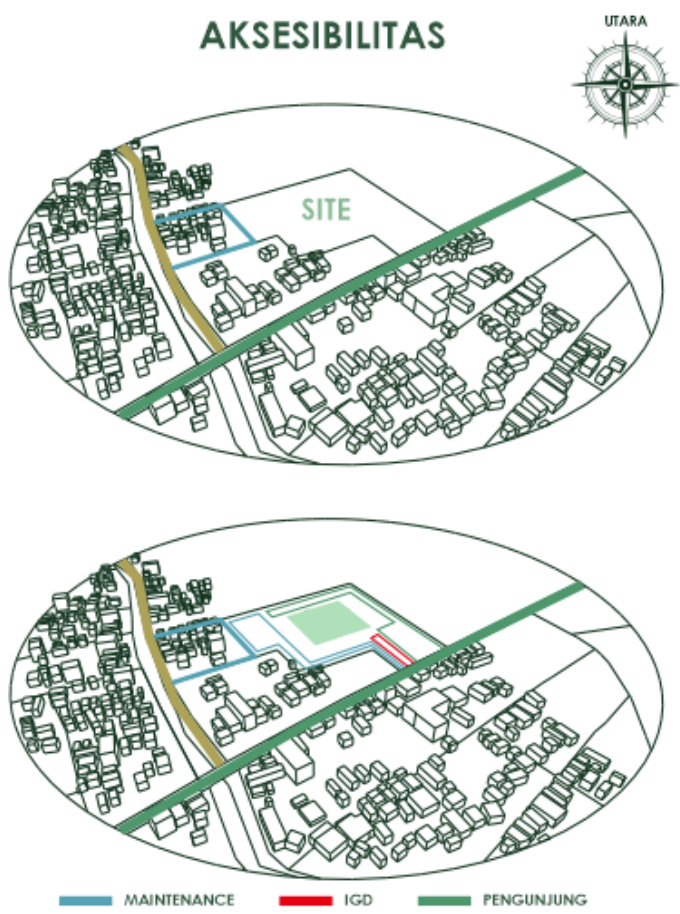

Gambar 3. Analisa dan Respon Aksesibilitas

Sumber: analisis, 2019 
4. Analisa dan respon view, infrastruktur dan drainase. Pada analisa view untuk menciptakan pemandangan yang dapat memulihkan pengguna dengan indera penglihtan, infrastruktur untuk mempermudah akses dalam bangunan dan drainase untuk memperlancar sirkulasi air agar tidak terjadi genangan maupun banjir yang dapat dilihat pada gambar 4 .
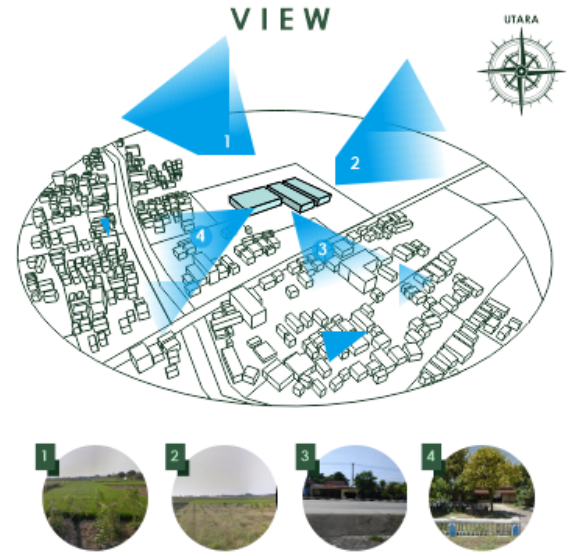

RESPON

Bangunan pada site nantinya menghadap ke selatan karena zona emergency harus terkoneksi dan dekat dengan akses utama. Zona publik dan semi publik diletakkan pada area utara dan bara agar mendapatkan view alami.

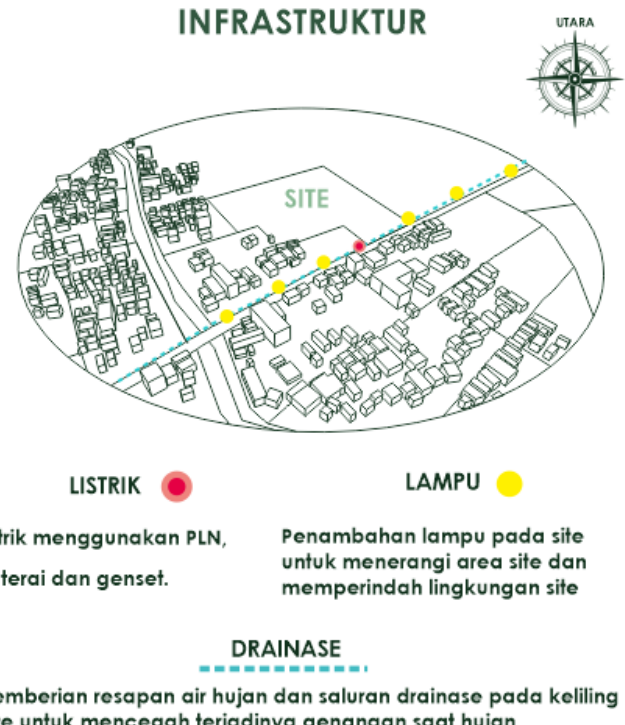

site untuk mencegah terjadinya genangan saat hujan

Gambar 4. Analisa dan Respon View, Infrastruktur dan Drainase

Sumber: analisis, 2019

5. Analisa dan respon kebisingan sehingga dapat mengurangi tingkat kebisingan yang ada pada sekitar bangunan sehingga pengguna dalam bangunan dapat relax / tenang yang dapat dilihat pada gambar 5 .

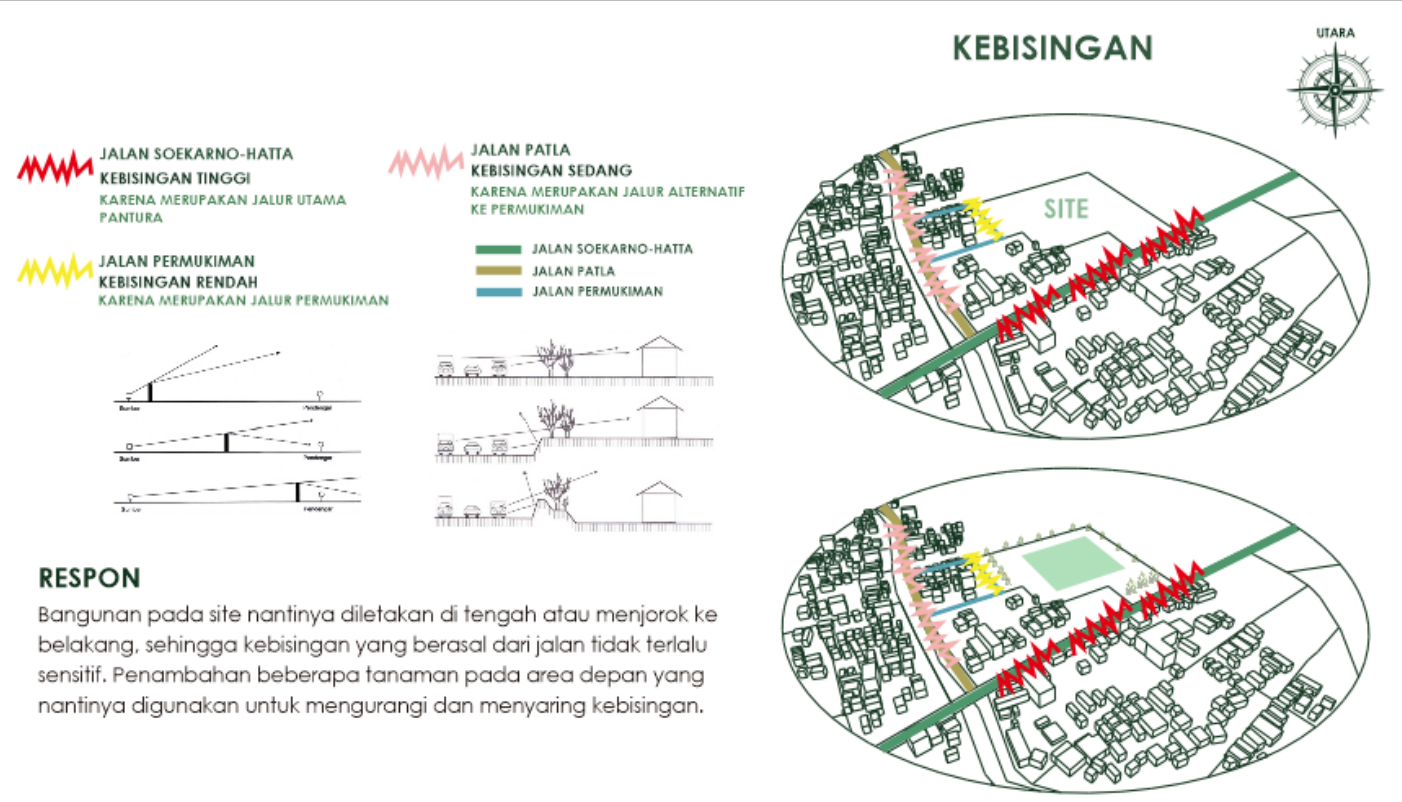

Gambar 5. Analisa dan Respon Kebisingan

Sumber: analisis, 2019

\subsection{Konsep Desain}

1. Konsep Fasad

Konsep fasad bangunan merupakan wajah ataupun ciri khas untuk mengidentifikasi jenis maupun fungsi bangunan yang dapat terlihat dari bentuk secondary skin dan warna pada fasad bangunan. Pada fasad 
rumah sakit ditonjolkan dengan pemberian secondary skin dan pemilihan warna, diantaranya sebagai berikut:

\section{a. Secondary skin}

Secondary skin pada luar bangunan digunakan untuk merespon sinar matahari secara tidak langsung serta sebagai penambahan nilai estetika bangunan sebagai fungsi pelayanan kesehatan masyarakat. Material yang digunakan untuk secondary skin yaitu kayu yang disusun secara horizontal, vertikal maupun zigzag.

b. Warna Fasad

Pemilihan warna pada fasad bangunan sangat berpengaruh terhadap proses penyembuhan. Warna yang diambil untuk fasad bangunan yaitu warna putih, abu-abu dan biru. Bangunan rumah sakit didominasi oleh warna putih yang berarti memberikan kesan higienis dan steril sehingga terkesan lebih tinggi dari sebenarnya. Warna biru memberi efek menenangkan dan dapat meningkatkan konsentrasi pengguna. Pemberian warna abu-abu bersifat netral dan tegas serta meningkatkan respon psikologis.

Konsep gubahan massa dan fasad memiliki proses sehingga tercipta bentukan dan tampilan yang menandakan suatu fungsi bangunan yang dapat dilihat pada gambar 6 .

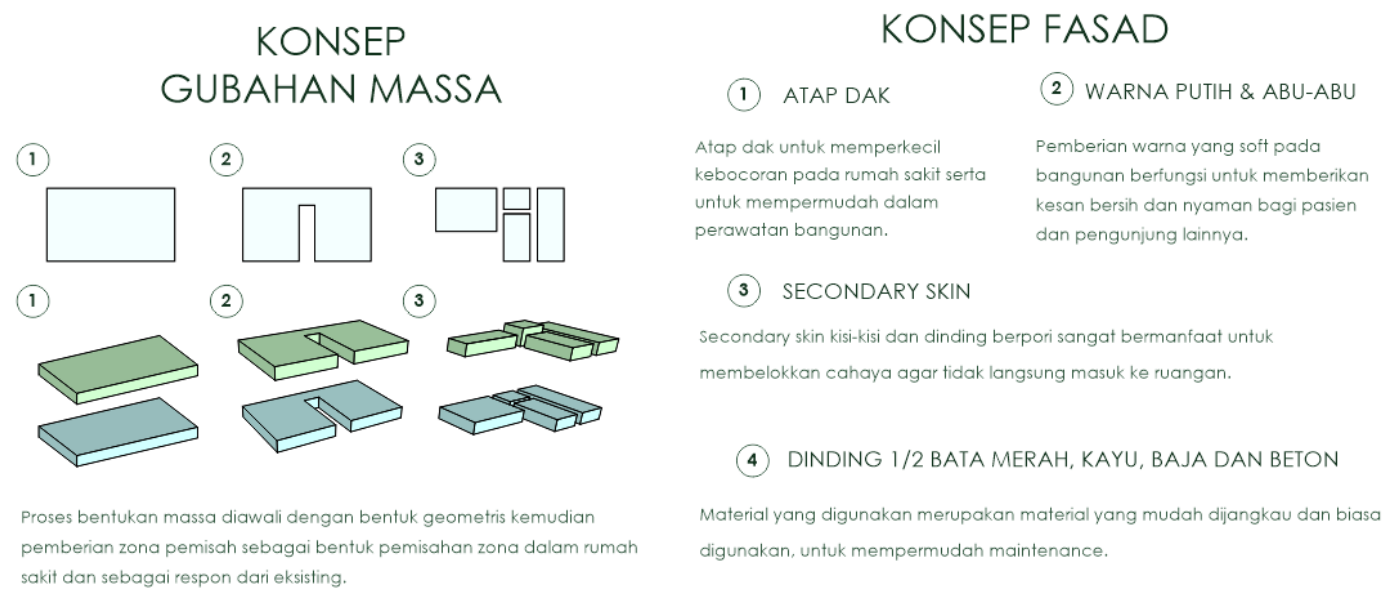

Gambar 6. Konsep Gubahan Massa dan Fasad Sumber: analisis, 2019

Penerapan konsep bangunan pada rumah sakit menggunakan konsep healing architecture yang dimana diterapkan langsung pada bangunan yang dapat dilihat pada gambar 7 .
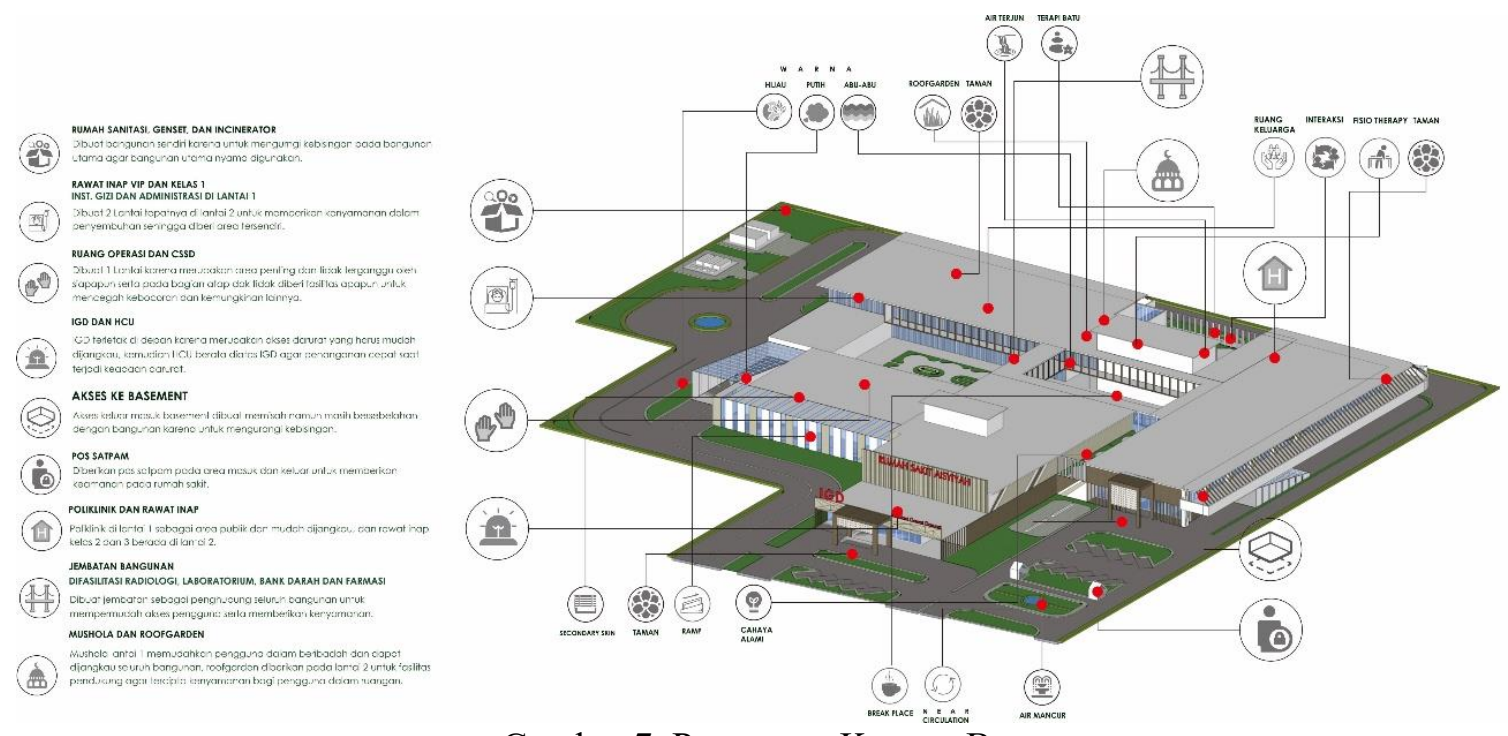

Gambar 7. Penerapan Konsep Bangunan

Sumber: analisis, 2019 


\section{Konsep Healing Architecture}

\section{a. People}

Pasien menjadi keutamaan peran pada bangunan rumah sakit dalam menjalani proses pengobatan hingga mencapai kesembuhan

b. Process

Proses penyembuhan yang digunakan melalui proses psikis dan fisik yaitu pada psikologi atau mental dan terapi fisik yang berpengaruh terhadap indera manusia pada desain yang diterapkan untuk membantu pemulihan pasien.

c. Place

Konsep healing architecture pada place diterapkan pada ruang dalam dan pada ruang luar bangunan. Pada ruang dalam bangunan atau interior menggunakan warna putih sehingga efeknya dapat meredakan rasa nyeri, steril, aura kebebasan dan keterbukaan hadir dalam ruangan, warna hijau mengefek pada batiniah yang terhubung erat dengan alam sehingga diaplikasikan pada area terbuka dan bebas, dan warna biru melambangkan ketenangan, kepercayaan dan konsentrasi.

Pada ruang luar yang diterapkan pada bangunan yaitu pengaplikasian taman bunga sebagai indera penglihatan yang memberikan dampak positif bagi pasien dalam proses penyembuhan. Kolam ikan dan terapi ikan sebagai indera penglihatan, pendengaran dan peraba memberikan efek senang, mengurangi stress, menjaga kesehatan kulit, memperlancar sirkulasi darah, menenangkan pikiran dll. Pemberian air terjun dan air mancur sebagai indera pendengaran dan penglihatan memberikan efek nyaman dan tenang. Dan penambahan terapi batu sebagai indera peraba memiliki manfaat membuang racun, memperlancar sirkulasi darah, menghilangkan kelelahan, meningkatkan metabolisme tubuh, memperlancar ekskresi, menegakkan postur tubuh dll.

Pemilihan furniture yang diterapkan yaitu dinding lukis, furniture alam buatan, penyediaan ruang keluarga, serta pencahayaam alami jendela dan skylight. Pemilihan tanaman yang diletakkan pada interior berupa crasulla argenta, lili paris, bromeliad, dracaena, ficus fern dan daun ivy. Aromaterapi yang digunakan pada interior bangunan yaitu bunga lavender, kamomil, pohon teh, daun mint, rosemary dll. Macam-macam tanaman interior dapat dilihat pada gambar 8.

\begin{tabular}{|c|c|c|c|c|c|}
\hline No & Jenis Tanaman & Manfaat & No & Jenis Tanaman & Manfaat \\
\hline 1 & $\begin{array}{l}\text { Crasulla Argentea } \\
\text { (tanaman jade }\end{array}$ & \multirow{2}{*}{$\begin{array}{l}\text { Sangat baik menyerap } \\
\text { toluena (bahan kimia } \\
\text { dengan aroma yang kuat } \\
\text { dan khas) } r \text { yang } \\
\text { dipancarkan oleh mobil, } \\
\text { bensin, minyak tanah, } \\
\text { minyak pemanas, cat dan } \\
\text { lak. }\end{array}$} & 5 & $\begin{array}{c}\text { Lily } \\
\text { (Spathhiphyllum } \\
\text { wallisii) }\end{array}$ & \multirow[b]{2}{*}{$\begin{array}{l}\text { Spathhiphyllum wallisii } \\
\text { dapat membantu tetap sehat. } \\
\text { Tanaman ini menyerap } \\
\text { radiasi elektromagnetik } \\
\text { yang dipancarkan oleh } \\
\text { komputer dan menjaga } \\
\text { udara lembab. }\end{array}$} \\
\hline & & & & & \\
\hline 2 & Lili Paris & \multirow[b]{2}{*}{ 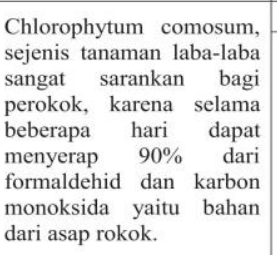 } & 6 & Daun Ivi & \multirow[b]{2}{*}{$\begin{array}{l}\text { Tanaman untuk perokok } \\
\text { atau mereka yang sensitif } \\
\text { terhadap asap. Tanaman ini } \\
\text { dianjurkan untuk yang } \\
\text { memiliki asma. }\end{array}$} \\
\hline & & & & & \\
\hline 4 & Dracaena & \multirow{2}{*}{$\begin{array}{l}\text { Tanaman ini dapat } \\
\text { menyerap lebih dari } 90 \% \\
\text { aseton yang sering } \\
\text { ditemukan dalam produk } \\
\text { seperti cat kuku atau alat } \\
\text { pembersih. }\end{array}$} & 7 & Philodendron & \multirow{2}{*}{$\begin{array}{lr}\text { Philodendron } & \text { scandens } \\
\text { efektif dalam menyerap } \\
\text { formalin, yang umumnya } \\
\text { ditemukan di produk } \\
\text { pembersih dan kompor gas. }\end{array}$} \\
\hline & & & & & \\
\hline \multirow[t]{2}{*}{5} & $\begin{array}{l}\text { Fern (Tanaman } \\
\text { Pakis) }\end{array}$ & \multirow[b]{2}{*}{$\begin{array}{l}\text { Tanaman ini baik untuk } \\
\text { meningkatkan } \\
\text { kelembaban udara. }\end{array}$} & 8 & Pohon Palm & \multirow[b]{2}{*}{$\begin{array}{l}\text { Tanaman ini menimbulkan } \\
\text { kesan berlibur di area bebas } \\
\text { serta membantu mengatur } \\
\text { tingkat kelembaban. }\end{array}$} \\
\hline & & & & & \\
\hline
\end{tabular}

Gambar 8. Macam-macam Tanaman Interior

Sumber: analisis, 2019 


\section{Konsep Struktur Bangunan}

Struktur bangunan menggunakan sistem rigid frame karena sistem ini memiliki ketahanan yang cukup kuat untuk bangunan bertingkat serta sangat efektif apabila diterapkan pada bangunan rumah sakit. Dilatasi diterapkan pada bangunan rumah sakit ini karena memiliki bentang panjang untuk menghindari terjadinya kerusakan secara menyeluruh. Konsep struktur bangunan pada rumah sakit menggunakan pondasi footplat karena terdiri dari dua lantai dan satu basement. Pada sistem bangunan ini menggunakan sistem kolom dan balok menggunakan cor beton, atap menggunakan dak, plat lantai menggunakan plat beton bertulang. Pada plafon menggunakan meterial gypsum, GRC board dan ekspose beton. Lantai menggunakan material lantai keramik. Explodametri struktur bangunan dapat dilihat pada gambar 9.

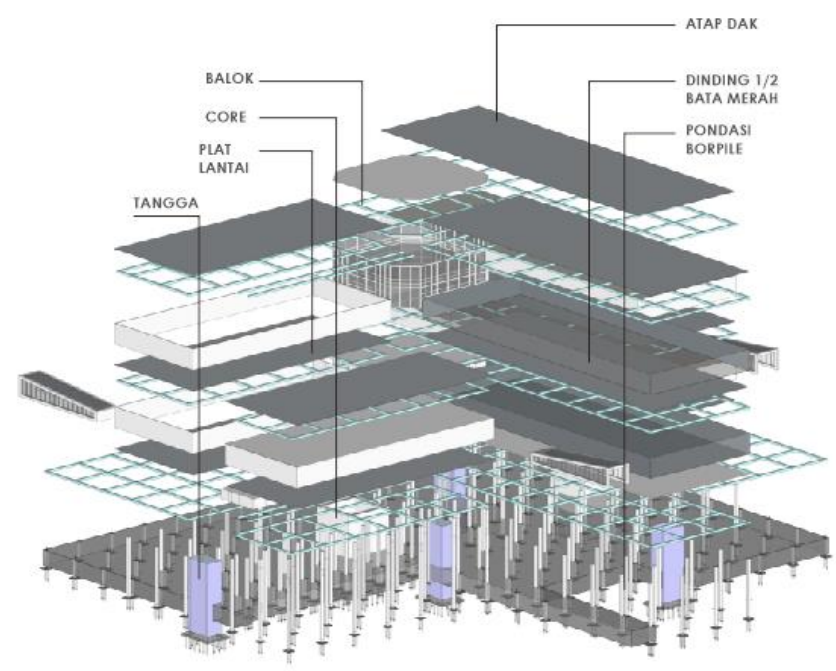

Gambar 9. Explodametri Struktur Bangunan

Sumber: analisis, 2019

4. Konsep Utilitas Bangunan

Konsep utilitas bangunan rumah sakit menggunakan sistem pengolahan limbah medis dan non medis jenis padat (kering maupun basah) yaitu menggunakan medin incinerator. Pada sistem ditribusi air bersih menggunankan downfeed dan air kotor dengan sistem sewage. Untuk sistem keamanan menggunakan cctv. Pada sistem keamanan penanggulangan kebakaran menggunakan tangga darurat, sign/tanda, fire detectore dan smoke detectore, sprinkler, hydrant dan apar. Pada sistem transportasi dan aksesibilitas yang digunakan yaitu tangga, lift dan ram. Sistem elektrikal bersumber dari PLN dan generator set. Sistem gas medik yang digunakan yaitu oksigen manifold, sistem pengamanan distribusi dan medical gas outlet. Sistem telekomunikasi yang digunakan yaitu telephone system, airphone dan gelombang radio pendek. Dan sistem penghawaan yang digunakan yaitu $a c$ vrv pada ruangan yang besar dan sesuai kebutuhan, $a c$ split diletakan pada ruangan dengan penghawaan secukupnya, exhaust fan diletakkan pada toilet gudang, basement dll. Explodametri utilitas bangunan dapat dilihat pada gambar 10.

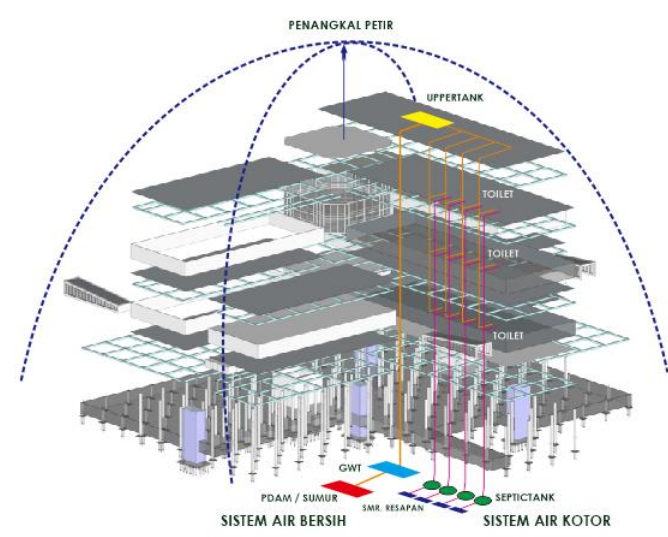

Gambar 10. Explodametri Utilitas Bangunan Sumber: analisis, 2019 
5. Konsep Healing Architecture

Konsep healing architecture pada rumah sakit dapat dilihat pada gambar 11. Konsep tersebut merupakan proses analisis yang memudahkan perancang dalam menerapkan healing architecture pada bangunan rumah sakit sehingga arah dan tujuan dari penerapan dalam perancangan dapat terbaca dengan jelas.

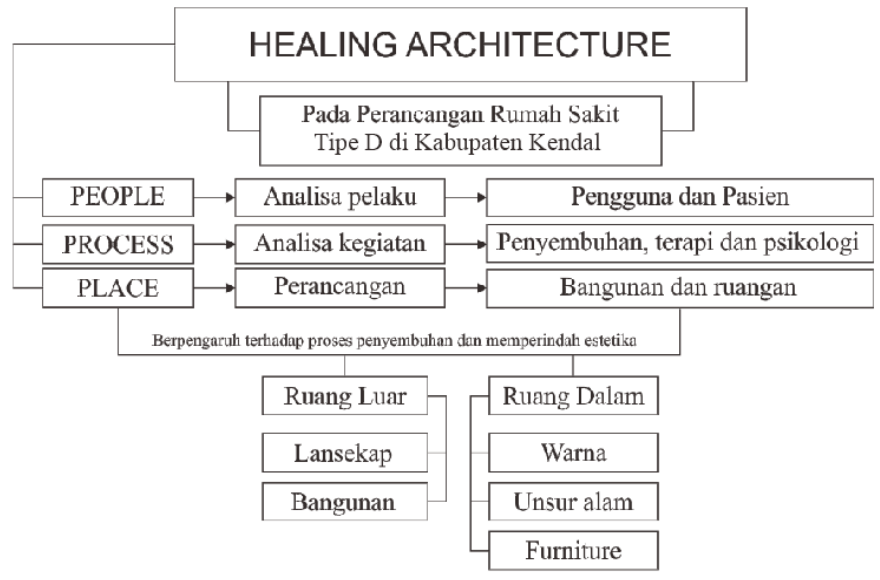

Gambar 11. Konsep Healing Architecture

Sumber: analisis, 2019

Pada gambar 12 konsep tapak merupakan hasil dari analisis yang berupa desain keseluruhan site tampak atas. Konsep tapak yang tercipta memiliki desain geometris yang mampu menampung kebutuhan pengguna dengan penerapan konsep healing architecture.

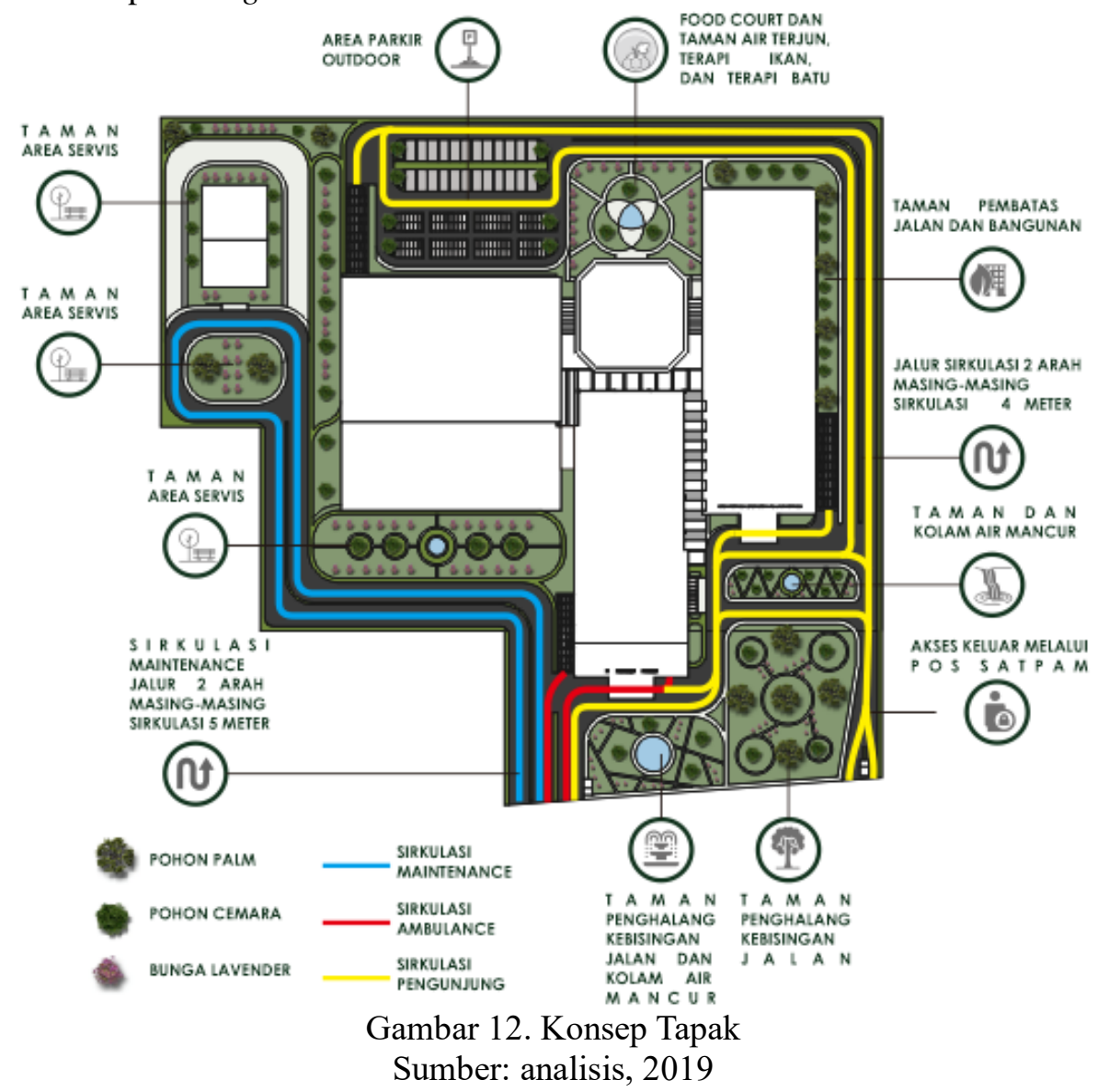

Bangunan 3 dimensi bangunan rumah sakit dengan penerapan konsep healing architecture dapat dilihat pada gambar 13. 


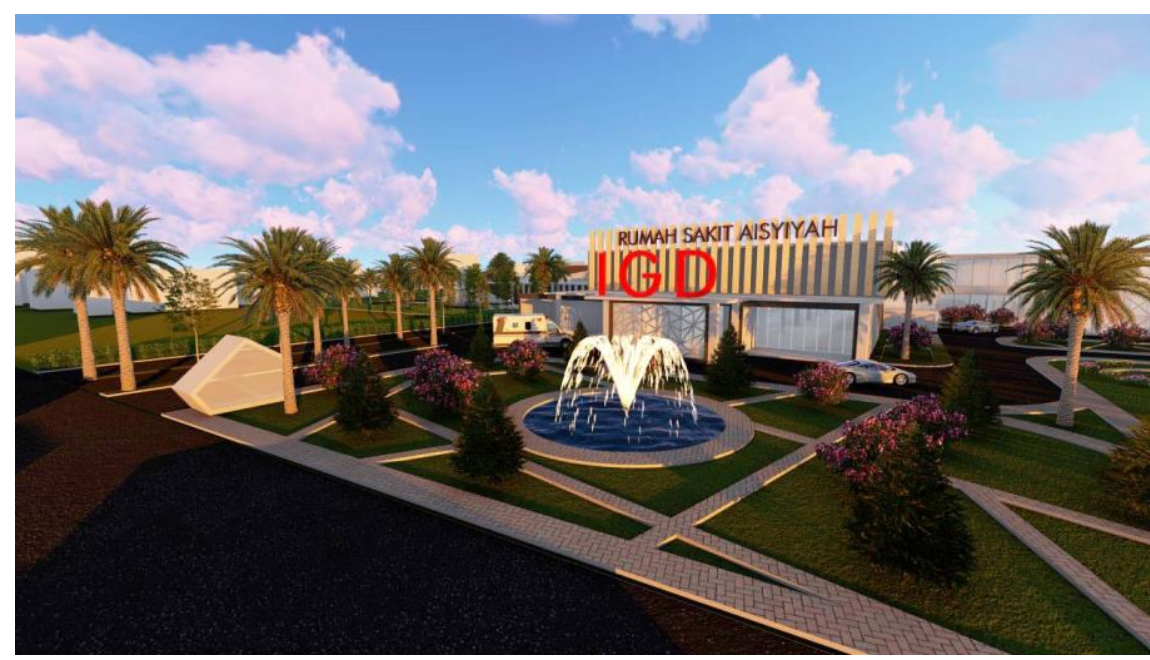

Gambar 13.3D Bangunan

Sumber: analisis, 2019

\section{Kesimpulan}

Kesimpulan dari Penerapan Konsep Healing Architecture Pada Rumah Sakit Tipe D di Kabupaten Kendal yaitu dimana tercipta karena adanya people, process dan place yang dianalisis serta diterapkan pada bangunan rumah sakit yang tentunya memiliki standar khusus sehingga dapat tercipta suatu desain dengan bentukan massa bangunan yang sesuai dengan kebutuhan serta berbentuk geometris dan tetap memunculkan bentuk yang menarik. Pemecahan bangunan terbentuk dari analisis dan kebutuhan ruang sehingga memunculkan ruang terbuka pada area tengah bangunan yang dimaksudkan untuk membantu proses penyembuhan secara healing architecture. Pada ruang dalam dibuat semi terbuka agar pengguna dapat berinteraksi dengan alam tanpa terhalang dinding dan penghalang lainnya. Penambahan ornamen dan pemberian warna yang soft membantu penyembuhan dalam proses psikologi dan terapi fisik. Bentuk massa bangunan tidak hanya massif namun dapat ditambah dengan bentuk menonjol dan menjorok sehingga tidak monoton dan berkesan saat dilihat.

\section{Referensi}

Anand, Dipesh. (2013). Healing Architecture in Hospital Design. Guru Govind Singh Indraprastha University Delhi. https://www.slideshare.net/DipeshAnand1/healing-architecture-for-hospital, Acces Date $15 / 06 / 2019$

Asma, Arinal Haq \& Sudarma, Erwin. (2017). Penerapan Healing Architecture dalam Desain Rumah Sakit. Jurnal Sains dan Seni ITS Vol. 6, No. 1. (2017) 2337-3520 (2301-928X Print).

Hastuti, Ummi. (2018). Kendal Dalam Angka 2018. Kendal. Badan Pusat Statistik Kabupaten Kendal.

Lou, Podbelski Vice. (2017). Architecture Solutions at Sageglass, https://www.sageglass.com/en/article/healing-architecture-hospital-design-and-patient-outcomes, Acces Date 15/06/2019.

Mulyani, Sri (2017). Profil Kesehatan Kabupaten Kendal Tahun 2016. Kendal. Dinas Kesehatan Kabupaten Kendal.

Mulyati. (2009). Peran Warna Pada Interior Rumah Sakit untuk Mencapai Kenyamanan dalam Kaitannya Penyembuhan Pasien, https://journal.uny.ac.id/index.php/imaji/article/view/6642, Acces Date $15 / 06 / 2019$

Mustika \& Muffida. (2017). Aspek Alam sebagai Bagian pada Rumah Sakit. Universitas Brawijaya. Malang. Mazaya, Ulfa \& Setyawan, Wahyu. (2016). Arsitekur Untuk Membantu Menyembukan Kerusakan Psikis Pada Manusia. Jurnal Sains dan Seni ITS Vol. 5, No. 2. (2016) 2337-3520 (2301-928X Print).

Peraturan Menteri Kesehatan Republik Indonesia Nomor 134/MenKes/SK IV/1978 pasal 4 tentang Rumah Sakit Umum. Jakarta.

Peraturan Menteri Kesehatan Republik Indonesia Nomor 56 paragraf 4 Klasifikasi Rumah Sakit Umum Kelas D. Jakarta.

Undang-Undang No. 44 Tahun 2009 tentang Peraturan Rumah Sakit. Jakarta. 